\title{
A stochastic frontier approach to study the relationship between gastrointestinal nematode infections and technical efficiency of dairy farms
}

\author{
Mariska van der Voort, ${ }^{*} \dagger{ }^{1}$ Jef Van Meensel, ${ }^{*}$ Ludwig Lauwers, ${ }^{*} \dagger$ Jozef Vercruysse, $\ddagger$ \\ Guido Van Huylenbroeck, $†$ and Johannes Charlierł \\ *Social Sciences Unit, Institute for Agricultural and Fisheries Research (ILVO), Burg. Van Gansberghelaan 115, 9820 Merelbeke, Belgium \\ †Department of Agricultural Economics, Faculty of Bio-Engineering, Ghent University, Coupure Links 653, 9000 Ghent, Belgium \\ łDepartment of Virology, Parasitology and Immunology, Faculty of Veterinary Medicine, Ghent University, Salisburylaan 133,9820 Merelbeke, \\ Belgium
}

\begin{abstract}
The impact of gastrointestinal (GI) nematode infections in dairy farming has traditionally been assessed using partial productivity indicators. But such approaches ignore the impact of infection on the performance of the whole farm. In this study, efficiency analysis was used to study the association of the GI nematode Ostertagia ostertagi on the technical efficiency of dairy farms. Five years of accountancy data were linked to GI nematode infection data gained from a longitudinal parasitic monitoring campaign. The level of exposure to GI nematodes was based on bulk-tank milk ELISA tests, which measure the antibodies to $O$. ostertagi and was expressed as an optical density ratio (ODR). Two unbalanced data panels were created for the period 2006 to 2010 . The first data panel contained 198 observations from the Belgian Farm Accountancy Data Network (Brussels, Belgium) and the second contained 622 observations from the Boerenbond Flemish farmers' union (Leuven, Belgium) accountancy system (Tiber Farm Accounting System). We used the stochastic frontier analysis approach and defined inefficiency effect models specified with the Cobb-Douglas and transcendental logarithmic (Translog) functional form. To assess the efficiency scores, milk production was considered as the main output variable. Six input variables were used: concentrates, roughage, pasture, number of dairy cows, animal health costs, and labor. The ODR of each individual farm served as an explanatory variable of inefficiency. An increase in the level of exposure to GI nematodes was associated with a decrease in technical efficiency. Exposure to GI nematodes constrains the productivity of pasture, health, and labor but does not cause inefficiency in the use of concentrates, roughage, and dairy cows. Lowering the level of infection in the interquartile range ( 0.271
\end{abstract}

Received August 29, 2013.

Accepted February 12, 2014.

${ }^{1}$ Corresponding author: mariska.vandervoort@ilvo.vlaanderen.be
ODR) was associated with an average milk production increase of 27, 19, and $9 \mathrm{~L} /$ cow per year for Farm Accountancy Data Network farms and 63, 49, and $23 \mathrm{~L} /$ cow per year for Tiber Farm Accounting System farms in the low- (0-90), medium- (90-95), and high- (95-99) efficiency score groups, respectively. The potential milk increase associated with reducing the level of infection was higher for highly efficient farms $(6.7 \%$ of the total possible milk increase when becoming fully technically efficient) than for less efficient farms (3.8\% of the total possible milk increase when becoming fully technically efficient).

Key words: Ostertagia ostertagi, stochastic frontier analysis, technical efficiency, animal health economics

\section{INTRODUCTION}

Volatile milk prices and an upward trend in production costs put pressure on dairy farmers' incomes (Thornton, 2010). Subtle changes in production efficiency can make the difference between profit and loss. Efficient dairy farming with an optimal management of inputs such as stock, feed, and labor has, therefore, become increasingly important (Kelly et al., 2013). Optimal management also requires taking care of animal health conditions, as these conditions may affect the economic performance of farms. This paper uses efficiency analysis to study the impact of gastrointestinal (GI) nematode infections on the technical efficiency of dairy farms.

Ostertagia ostertagi and Cooperia oncophora are considered to be the most important GI nematode species in dairy cattle in temperate climate regions (Charlier et al., 2011; Sargison, 2011). Although GI nematode infections generally stay at a subclinical level, they can be responsible for decreased feed intake and reduced milk production and fertility (Forbes et al., 2004; Charlier et al., 2009a; Delafosse, 2013). Research addressing the impact of GI nematode infections and related prevention strategies traditionally focuses on the effect on particular technical key performance indicators, such as 
daily weight gain and average milk yield per cow. Knowing the effects on these key performance indicators is useful (Charlier et al., 2012a,b) because they are often correlated with the aggregate economic performance of dairy farms (Bandyopadhyay et al., 2010). But an important drawback of this approach is that the key performance indicators are mostly partial measures of productivity. They do not represent the overall inputoutput transformation on dairy farms and, thus, the effect on the overall performance of the farm remains unclear (Van Meensel et al., 2010b).

Efficiency analysis can be used to analyze the impact of animal diseases on the performance of the whole farm (van der Voort et al., 2013). The approach is based on production theory, which studies the transformation of input(s) into output(s). Efficiency analysis bundles partial productivities into an aggregate performance measure. The advantage of efficiency analysis is the identification of performance benchmarks, which allow calculation of the farm-specific performance levels and optimization paths. Despite its frequent use in management science, efficiency analysis has not often been applied in animal health sciences. Methods for efficiency analysis evolve quickly. Today, numerous deterministic and stochastic approaches are available (Cook and Seiford, 2009; Darku et al., 2013; Liu et al., 2013). The growing interest in incorporating noneconomic factors in productive efficiency models has resulted in some studies that introduce animal health factors into efficiency analysis (e.g., Lawson et al., 2004a; Van Meensel et al., 2010a; Barnes et al., 2011).

The objective of this study was to analyze the relationship between GI nematode infection in dairy cattle and the technical efficiency level of dairy farms. We investigated to what extent the exposure to GI nematodes affects the transformation of inputs(s) into output(s) on dairy farms. We applied 2 functional forms of the production function, representing the input-output transformation, to study which model is best to frame the relationship between infection and efficiency.

\section{MATERIALS AND METHODS}

\section{Data}

To study the effect of animal health parameters on farm economics, it is essential to merge 2 (usually independently monitored) data sources. In our case, we used farm accounting data and animal health parameters. Here, the animal health parameter of interest was infection with the abomasal dwelling nematode Ostertagia ostertagi. The source of infection data was a yearly parasitic monitoring campaign, with sampling performed from 2006 to 2010 (Bennema et al., 2009).
In that campaign, the cows' exposure to GI nematodes was monitored using the antibody detection $O$. ostertagi ELISA (SVANOVIR O. ostertagi-Ab; Boehringer Ingelheim Svanova, Uppsala, Sweden) applied to bulktank milk as described by Charlier et al. (2009b). The test results of antibody detection serve to measure the antibodies to $O$. ostertagi and use optical density ratio (ODR) as a unit of measure. This provides an indication of the level of exposure of a herd to GI nematodes (Charlier et al., 2009a).

Farm accountancy data used in this study were collected from 2 networks: the Belgian Farm Accountancy Data Network (FADN, Brussels, Belgium) and the Tiber Farm Accounting System (TFAS) of Boerenbond (Leuven, Belgium), a Flemish farmers' union. The FADN data are based on a stratified sample and are representative for Flanders (De Becker, 2007), whereas the TFAS sample is based on voluntary participation in the farm-economic accounting system of Boerenbond. When farms from FADN or TFAS were also present in the infection data set, they were included in our study. As FADN and TFAS do not apply the same accounting principles, data from these 2 sources could not be included in 1 sample. Therefore, we constructed 2 data samples that linked FADN and TFAS data to the parasitic information. The final data sets were constructed using several inclusion criteria. First, individual farm data from at least 2 consecutive years had to be present to construct a panel data set. Second, farms with input variables equal to 0 were excluded. Third, 1 FADN farm in the year 2009 was considered as an outlier. It was deleted from the data set because in the year 2009, this farm doubled in size and almost tripled its input use. This could also be empirically observed: compared with the other farms in the sample, this farm had a deviated input/output use.

The final data sets consisted of technical, economic, and parasitic farm data of 50 FADN and 152 TFAS dairy farms. As data were not available for each farm for each year during the period 2006 to 2010, we constructed unbalanced data panels consisting of 198 FADN and 622 TFAS observations.

\section{Efficiency Analysis}

Efficiency analysis is based on production theory. It compares the current performance level of a farm with the potential optimal performance level by determining a production frontier (Farrell, 1957). The production frontier represents the fully technically efficient transformation of input(s), such as feed or labor, into output(s), such as milk or meat, in the dairy farm industry at a particular point in time. Farms situated on (or close to) this frontier achieve the best technical 
performance level possible in the dairy farm and are called technically efficient. Farms situated beneath the production frontier are technically inefficient, but can change their efficiency by moving closer to the frontier by improving their input-output transformation. Producing the maximal amount of output(s) with a given amount of input(s) is called output-oriented technical efficiency, whereas the ability to use a minimal amount of input(s) to obtain a given amount of output(s) is called input-oriented technical efficiency. The efficiency score is a measure between 0 and 1 , where 0 indicates total inefficiency and 1 total efficiency.

The technical efficiency score is calculated for each individual farm by (1) determining the frontier and (2) measuring the distance between each farm and the efficiency frontier. To assess the frontier and calculate efficiency scores for a given set of data, the literature distinguishes between 2 conventional approaches: nonparametric data envelopment analysis (DEA) and parametric stochastic frontier (SF) analysis (Kumbhakar and Lovell, 2000; Coelli et al., 2005). Data envelopment analysis involves linear programming to construct a nonparametric piecewise frontier enveloping the data and calculates its efficiency scores relative to this frontier. Disadvantages of DEA are its sensitivity to outliers and the ignorance of stochastic noise. Stochastic frontier analysis uses econometrics to estimate the efficiency frontier. The main advantage of SF analysis is that it takes both inefficiency and statistical noise into account. However, SF analysis requires an a priori specification of the functional form of the production function by the researcher.

The differences in technical inefficiency between farms can be explained by incorporating explanatory variables, such as animal disease data and management information, into the efficiency model. The literature describes 2 methods to explain inefficiency: the 2-step approach and the inefficiency effect model. In the 2-step approach, efficiency scores are assessed first using either DEA or SF analysis. Subsequently, the scores are regressed on explanatory variable(s) using a linear regression or a censored (Tobit) model (Barnes et al., 2011; Kelly et al., 2012). The 2-step approach has some shortcomings, however (Simar and Wilson, 2007; Schmidt, 2011). First, the results from the method become biased when the inputs from the efficiency analysis are correlated with second-stage explanatory variables. Second, the effect of the explanatory variable on efficiency will be underestimated. The 1-step approach applied with SF analysis, the "inefficiency effect" model (Kumbhakar et al., 1991; Battese and Coelli, 1995; Wang and Schmidt, 2002), overcomes these problems. The inefficiency effect model allows for the simultaneous estimation of the production frontier and effect of explanatory variables on the efficiency scores. This inefficiency effect model is considered to be more appropriate to determine the relationship between production efficiency and explanatory variables such as GI nematode infection (Kumbhakar et al., 1991).

\section{Efficiency Models}

The general production model of SF analysis was defined by

$$
Y_{i t}=\exp \left(\mathbf{x}_{i t} \beta+V_{i t}-U_{i t}\right),
$$

where subscript $i$ denotes the 50 (FADN) and 152 (TFAS) farms and $t$ indicates the time in years from 2006 until 2010, $Y_{i t}$ is the output level of farms, $\mathbf{x}_{i t}$ represents a vector of inputs, $\beta$ represents an unknown parameter to be estimated, $V_{i t}$ represents random noise and is assumed to be independent and identically distributed with a normal distribution with mean zero and unknown variance $\left(\sigma^{2}\right)$, and $U_{i t}$ represents the technical inefficiency scores.

To assess efficiency scores, milk production in liters of fat- and protein-corrected milk was considered as the output variable (dependent variable). We considered only 1 output because from a production-economic viewpoint, the objective of specialized dairy farms is to produce milk. Moreover, for the farms in our data set, $86 \%$ of farm income came from milk sales. The remaining returns were from changes in animal value $(12 \%)$ and other returns (i.e., premiums and cow sales; $2 \%$ ). Our model included 6 input variables (independent variables): concentrate and roughage, both defined as kilograms of feed consumed; pasture, defined as hectares of grazed grassland; dairy cows, defined by the number of lactating dairy cows present on the farm; dairy health, defined as the cost for veterinary services and medicines; and labor, defined as labor (in hours) performed by family and hired labor. These inputs were selected based on explorative research done by (1) performing econometric analyses that indicated which inputs were significantly correlated with the amount of milk produced, (2) considering variables related to GI nematode infections, and (3) considering variables that a farmer can adapt for short-term control of the infection. Descriptive statistics of the output and input variables are presented in Table 1 for the 2 data sets. When analyzing the results of our study, note that FADN and TFAS both have different definitions of the input variables roughage and pasture. These definitions lie behind each system's calculations. In the TFAS accountancy system, data were not available for kilograms of roughage consumption; only the total costs for producing each feed product were considered. To 
Table 1. Descriptive statistics of farm production variables for Farm Accountancy Data Network (FADN, Brussels, Belgium) and Tiber Farm Accounting System (TFAS; Boerenbond, Leuven, Belgium) populations in the stochastic frontier production function expressed per year

\begin{tabular}{lccccc}
\hline Variable $^{1}$ & Symbol & Mean & SD & Minimum & Maximum \\
\hline FADN population & & & & & \\
ECM (L) & $Y$ & 304,927 & 144,010 & 68,189 & 658,215 \\
Concentrate per cow (kg) & $x_{1}$ & 1,886 & 1,329 & 179 & 6,933 \\
Roughage per cow (kg) & $x_{2}$ & 7,978 & 2,567 & 1,260 & 16,487 \\
Pasture per cow (ha) & $x_{3}$ & 0.129 & 0.064 & 0.017 & 0.319 \\
Number of dairy cows per herd & $x_{4}$ & 44.40 & 16.58 & 18.38 & 84.14 \\
Animal health cost per cow (\$) & $x_{5}$ & 73.28 & 42.02 & 7.65 & 228 \\
Labor per cow (h) & $x_{6}$ & 55.14 & 30.94 & 7.08 & 219 \\
GI nematode infection (ODR) & $z_{1}$ & 0.848 & 0.181 & -0.159 & 1.326 \\
TFAS population & $Y$ & 484,770 & 267,885 & 84,109 & 680,739 \\
ECM (L) & $x_{1}$ & 1,277 & 396 & 357 & 2,504 \\
Concentrate per cow (kg) & $x_{2}$ & 4,195 & 1,371 & 979 & 10,082 \\
Roughage per cow (kg) & $x_{3}$ & 0.158 & 0.055 & 0.020 & 0.347 \\
Pasture per cow (ha) & $x_{4}$ & 62.31 & 31.55 & 21.42 & 91.58 \\
Number of dairy cows per herd & $x_{5}$ & 66.99 & 30.68 & 9.52 & 190 \\
Animal health cost per cow (\$) & $x_{5}$ & 53.28 & 23.06 & 11.72 & 164 \\
Labor per cow (h) & $x_{6}$ & 0.737 & 0.223 & 0.034 & 1.326 \\
GI nematode infection (ODR) & $z_{1}$ & & & & \\
\hline
\end{tabular}

${ }^{1} \mathrm{GI}=$ gastrointestinal; ODR $=$ optical density ratio.

address this, we calculated the kilograms of roughage by using the average price per kilogram of maize and other roughage products from the FADN population. For farms using the FADN accountancy system, the variable pasture included the amount of hectares used for grazing. For TFAS farms, this variable also included hectares of pasture used for roughage cultivation.

To determine the relationship between the efficiency level of farms and the GI nematode infection, we considered 2 inefficiency effect models (i.e., the neutral stochastic frontier model and the non-neutral stochastic frontier model). These models differ in the specification of technical inefficiency scores, represented by $U_{i t}$ in the general production model. The neutral stochastic frontier model assumes that the inefficiency effects due to the explanatory variable are independent of the input variables. The non-neutral stochastic frontier model is an extension of the neutral stochastic frontier model by including the interaction between the level of exposure to GI nematodes and the input variables. This model assumes that the impact of GI nematode infections can either limit or encourage the transformation of certain inputs into the output "milk."

In the neutral stochastic frontier model, the inefficiency effects were estimated as a function of the input variables and the explanatory variable (GI nematode exposure) believed to influence the technical inefficiency. This model is defined by

$$
U_{i t}=\delta_{0}+\delta_{1} z_{i t}+W_{i t}
$$

where $z_{i t}$ is the level of exposure to GI nematodes associated with the technical inefficiency effects, $\delta$ is the unknown parameters to be estimated, and $W_{i t}$ are unobservable random variables. The technical inefficiency effects are assumed to be independent nonnegative truncations of normal distributions with unknown variance and means. The mean may be different for different farms and time periods, but the variances are assumed to be the same.

In the non-neutral stochastic frontier model, the cross products of GI nematodes and the input variables are included in the inefficiency function. This model is defined by

$$
U_{i t}=\delta_{0}+\delta_{1} z_{i t}+\delta^{*} \mathbf{z}_{i t}^{*}+W_{i t}
$$

where $\mathbf{z}_{i t}^{*}$ is a vector of interactions between the variables in $z_{i t}$ and $x_{i t}$, and all other terms are as defined above.

To calculate the marginal effect of the inefficiency on the output variable, the technical efficiency scores were partially differentiated with respect to each of the inefficiency effect variables, as described by Wilson et al. (2001).

\section{Functional Forms}

To calculate the stochastic production model for the 2 inefficiency effect models represented by Equations 2 and 3 , a functional form for the production function must be selected. The functional forms most commonly used in research on production efficiency of dairy farming are Cobb-Douglas (CD) and transcendental logarithmic [Translog (TL); Moreira López and Bravo-Ureta, 2009; Hoang and Nguyen, 2013]. The TL 
functional form is more flexible and makes fewer assumptions about the form of the production function. One might expect a better model using TL. But the TL model seems less appropriate for small data sets because more parameters have to be estimated, which requires more observation to get reliable estimates. In our study, both functional forms were used to study how the result may be affected by the model chosen and to identify the model that could best frame the relationship between GI nematode infections and efficiency (Battese and Broca, 1997). The CD production function is specified as

$$
\operatorname{Ln} Y_{i}=\beta_{0}+\sum_{j=i}^{6} \beta_{j} \operatorname{Ln} X_{j i t}+V_{i t}-U_{i t},
$$

where $Y$ is the total milk production (in liters), $X_{1-6}$ are the 6 input variables defined above, $V_{i t}$ is random noise, and $U_{\mathrm{it}}$ is the inefficiency term (see also Equations 2 and 3).

The TL functional form differs from the CD functional form in that second-order coefficients and interactions among the input variables are included. The TL functional form is defined as

$\operatorname{Ln} Y_{i}=\beta_{0}+\sum_{j=i}^{6} \beta_{j} \operatorname{Ln} X_{j i t}+\sum_{j=1}^{6} \sum_{k=1}^{6} \beta_{j k} \operatorname{Ln} X_{j i t} L n X_{k i t}+V_{i t}-U_{i t}$.

A likelihood ratio test was performed to compare the CD with the TL model. Four models were estimated for both the FADN and TFAS data sets: a neutral as well as a non-neutral production model for the CD and TL functional form. All models were estimated using maximum likelihood with the FRONTIER 4.1 computer program (Coelli, 1996).

\section{RESULTS}

\section{Technical Efficiency Scores}

The technical efficiency scores obtained using the CD and TL production function indicated the inefficiency of the dairy farms. The mean technical efficiency was 0.81 for FADN and 0.88 for TFAS farms. Using the current input quantities, the FADN and TFAS farms could increase their milk production level, on average, by 1,100 and $800 \mathrm{~L} /$ cow per year, respectively. These increases would bring these farms up to the level of their peers near the efficiency frontier.

Technical efficiency ranged from 0.24 (inefficient) to 0.98 (efficient; Figure 1). The results show that more than $61 \%$ of FADN farms and $42 \%$ of TFAS farms were

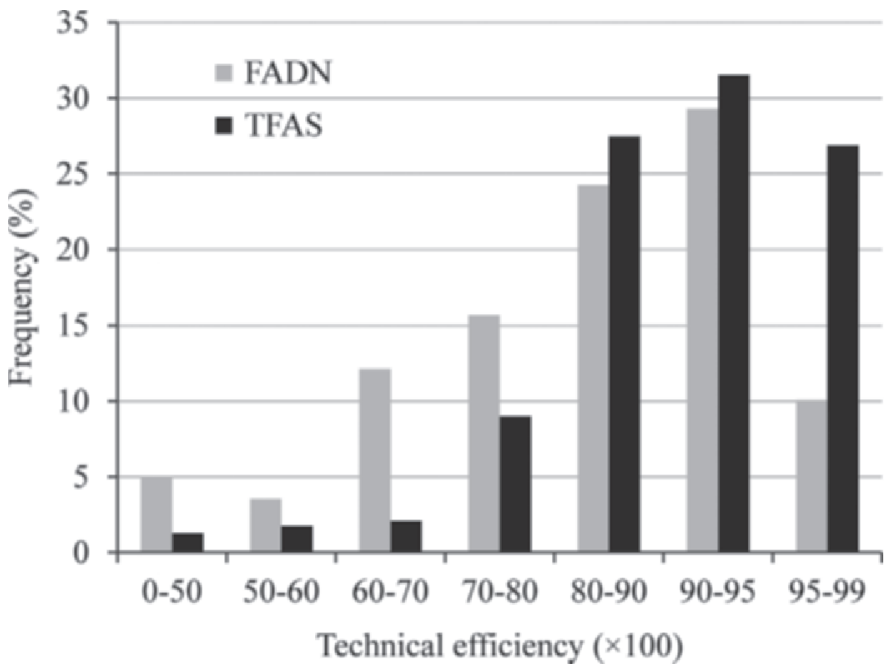

Figure 1. Distribution of technical efficiency of Farm Accountancy Data Network (FADN, Brussels, Belgium) and Tiber Farm Accounting System (TFAS; Boerenbond, Leuven, Belgium) farms.

below the efficiency score of 90 . Calculations show that the average milk loss due to inefficiency by FADN farms in low- (0-90), medium- (90-95), and high- (95-99) efficiency score groups was approximately 1,596, 811, and $498 \mathrm{~L} /$ cow per year, respectively. The TFAS average milk production losses were 1389, 690, and $376 \mathrm{~L} /$ cow per year, in the low-, medium-, and high-efficiency score groups, respectively.

\section{Production Model}

The maximum-likelihood estimates for the estimated CD and TL neutral production models for both accountancy data samples are presented in Table 2 . The first-order coefficients $\beta_{1}$ to $\beta_{6}$ are the estimated mean output elasticities. These elasticities represent the relative percentage change in the neutral mean output due to a relative percentage change in a particular input under the assumption that the other inputs are held constant.

The results of FADN show that the estimated mean output elasticities $\beta_{1}$ and $\beta_{4}$ of the CD model were positive and significantly different from zero $(P<0.01)$. The coefficients $\beta_{3}$ and $\beta_{6}$ were negative but nonsignificant. For the TFAS, all estimated coefficients of the CD model $\beta_{1}$ to $\beta_{6}$ were different from zero $(P<0.05)$. The input variables in the TFAS sample had a positive relationship with milk production, with the exception of labor. The estimated coefficient, 0.214 for $\beta_{1}$ of the CD model (see TFAS sample Table 2), is the estimated percentage increase in milk production due to a $1 \%$ increase in the amount of concentrate intake. This implies that when $10 \%$ additional concentrate is given, 
Table 2. The maximum likelihood estimates for the parameters in the neutral stochastic frontier model in terms of the Cobb-Douglas and transcendental logarithmic (Translog) functional form for both the Farm Accountancy Data Network (FADN, Brussels, Belgium) and Tiber Farm Accounting System (TFAS; Boerenbond, Leuven, Belgium) samples

\begin{tabular}{|c|c|c|c|c|c|c|c|c|c|}
\hline \multirow[b]{3}{*}{ Variable } & \multirow[b]{3}{*}{ Parameter } & \multicolumn{4}{|c|}{ FADN } & \multicolumn{4}{|c|}{ TFAS } \\
\hline & & \multicolumn{2}{|c|}{ Cobb-Douglas } & \multicolumn{2}{|c|}{ Translog } & \multicolumn{2}{|c|}{ Cobb-Douglas } & \multicolumn{2}{|c|}{ Translog } \\
\hline & & Coefficient $^{1}$ & SEM & Coefficient $^{1}$ & SEM & Coefficient $^{1}$ & SEM & Coefficient $^{1}$ & SEM \\
\hline Constant & $\beta_{0}$ & $7.436^{* *}$ & 0.549 & $-29.96^{* *}$ & 2.294 & $7.160^{* *}$ & 0.205 & $-62.20^{* *}$ & 9.900 \\
\hline Concentrate $(\mathrm{kg})$ & $\beta_{1}$ & $0.108^{* *}$ & 0.020 & $1.676^{* *}$ & 0.429 & $0.214^{* *}$ & 0.016 & 0.627 & 0.387 \\
\hline Roughage $(\mathrm{kg})$ & $\beta_{2}$ & $0.067 \dagger$ & 0.037 & $2.463^{*}$ & 1.069 & $0.044^{* *}$ & 0.015 & $0.896 \dagger$ & 0.528 \\
\hline Pasture (ha) & $\beta_{3}$ & -0.014 & 0.024 & 0.175 & 0.208 & $0.029^{*}$ & 0.015 & 0.179 & 0.111 \\
\hline Cows (no./herd) & $\beta_{4}$ & $0.870^{* *}$ & 0.053 & $-38.69^{* *}$ & 4.143 & $0.692^{* *}$ & 0.028 & -1.810 & 1.730 \\
\hline Animal health cost $(\$)$ & $\beta_{5}$ & 0.013 & 0.045 & $10.90 \dagger$ & 14.45 & $0.036^{* *}$ & 0.020 & $9.41^{* *}$ & 3.891 \\
\hline Labor $(\mathrm{h})$ & $\beta_{6}$ & -0.021 & 0.042 & 8.275 & 6.163 & $-0.051^{* *}$ & 0.017 & $8.670 \dagger$ & 4.920 \\
\hline (Concentrate) & $\beta_{11}$ & & & $-0.069^{* *}$ & 0.019 & & & -0.018 & 0.017 \\
\hline (Roughage) & $\beta_{22}$ & & & $-0.100^{*}$ & 0.044 & & & $-0.039 \dagger$ & 0.023 \\
\hline (Pasture) & $\beta_{33}$ & & & $0.064 \dagger$ & 0.034 & & & $-0.042^{*}$ & 0.020 \\
\hline (Cows) & $\beta_{44}$ & & & $4.693^{* *}$ & 1.440 & & & $2.070^{*}$ & 0.805 \\
\hline (Health) & $\beta_{55}$ & & & 0.738 & 1.010 & & & $-1.068^{*}$ & 0.698 \\
\hline (Labor) & $\beta_{66}$ & & & -0.749 & 1.118 & & & 0.152 & 0.772 \\
\hline Concentrate $\times$ roughage & $\beta_{12}$ & & & 0.015 & 0.014 & & & 0.010 & 0.007 \\
\hline Concentrate $\times$ pasture & $\beta_{13}$ & & & -0.003 & 0.011 & & & 0.005 & 0.005 \\
\hline Concentrate $\times$ cows & $\beta_{14}$ & & & -0.276 & 0.279 & & & $0.189^{* *}$ & 0.069 \\
\hline Concentrate $\times$ health & $\beta_{15}$ & & & -0.017 & 0.196 & & & $-0.272^{* *}$ & 0.099 \\
\hline Concentrate $\times$ labor & $\beta_{16}$ & & & -0.189 & 0.265 & & & $-0.282^{*}$ & 0.121 \\
\hline Roughage $\times$ pasture & $\beta_{23}$ & & & $-0.006^{*}$ & 0.002 & & & 0.000 & 0.002 \\
\hline Roughage $\times$ cows & $\beta_{24}$ & & & 0.119 & 0.090 & & & $0.151^{*}$ & 0.062 \\
\hline Roughage $\times$ health & $\beta_{25}$ & & & $-0.063^{* *}$ & 0.022 & & & $-0.045^{* *}$ & 0.017 \\
\hline Roughage $\times$ labor & $\beta_{26}$ & & & 0.057 & 0.080 & & & $0.149^{* *}$ & 0.049 \\
\hline Pasture $\times$ cows & $\beta_{34}$ & & & $-0.376^{*}$ & 0.183 & & & $0.211^{*}$ & 0.095 \\
\hline Pasture $\times$ health & $\beta_{35}$ & & & $0.208 \dagger$ & 0.115 & & & -0.067 & 0.072 \\
\hline Pasture $\times$ labor & $\beta_{36}$ & & & 0.018 & 0.068 & & & -0.021 & 0.046 \\
\hline Cows $\times$ health & $\beta_{45}$ & & & $-1.841 \dagger$ & 1.067 & & & -0.114 & 0.775 \\
\hline Cows $\times$ labor & $\beta_{46}$ & & & $7.296^{* *}$ & 1.571 & & & $-1.370 \dagger$ & 0.805 \\
\hline Health $\times$ labor & $\beta_{56}$ & & & $-4.009^{* *}$ & 1.343 & & & $-1.420^{*}$ & 0.634 \\
\hline \multicolumn{10}{|l|}{ Inefficiency model } \\
\hline Constant & & $-8.791 \dagger$ & 4.770 & $-7.788^{*}$ & 3.118 & $-5.110^{* *}$ & 1.410 & $-5.060^{* *}$ & 0.437 \\
\hline GI nematode infection $(\mathrm{ODR})^{2}$ & $\delta_{1}$ & $4.368^{*}$ & 2.106 & $4.178^{* *}$ & 1.558 & $3.660^{* *}$ & 0.941 & $3.340^{* *}$ & 0.124 \\
\hline Error variance & $\sigma_{e}$ & $1.340 \dagger$ & 0.691 & $1.061^{* *}$ & 0.400 & $0.372^{* *}$ & 0.092 & $0.364^{* *}$ & 0.060 \\
\hline Variance $^{3}$ & $\gamma^{3}$ & $0.994^{* *}$ & 0.004 & $0.996^{* *}$ & 0.003 & $0.990^{* *}$ & 0.003 & $0.990 * *$ & 0.003 \\
\hline Log-likelihood value & & 21.71 & & 46.77 & & 370 & & 412 & \\
\hline
\end{tabular}

${ }^{1}$ Negative signs of coefficients represent reduction in inefficiency (or increase in efficiency)

${ }^{2} \mathrm{GI}=$ gastrointestinal; ODR $=$ optical density ratio.

$\therefore{ }^{3} \mathrm{Gamma}$ is the variance parameters associated with inefficiency. It is zero if no inefficiency exists in the traditional error term.

$\underset{v}{\varphi} \dagger P<0.10 ; * P<0.05 ; * * P<0.01$. 

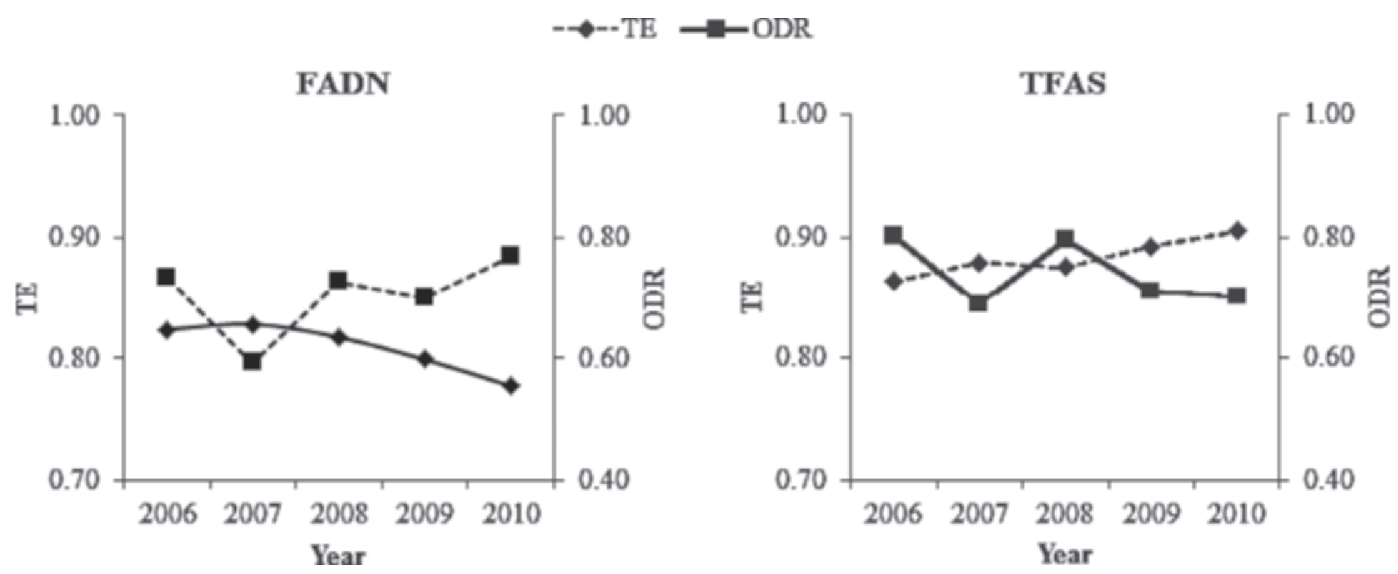

Figure 2. The mean technical efficiency (TE) and exposure to gastrointestinal (GI) nematodes (optical density ratio, ODR) from 2006 to 2010. FADN = Farm Accountancy Data Network (Brussels, Belgium); TFAS = Tiber Farm Accounting System (Boerenbond, Leuven, Belgium).

the marginal farm milk output increased, on average, by $10,374 \mathrm{~L}$ of milk $(484,770 \mathrm{~L}$ of milk $\times 0.214 \times 0.10)$.

The sum of the first-order coefficients, referred to as the scale elasticity, indicates whether the production model exhibits increasing, decreasing, or constant returns to scale. Returns to scale reflect the degree to which a proportional increase in all inputs increases output. The sum of the 6 first-order coefficients $\left(\beta_{1}\right.$ to $\beta_{6}$ ) under both the CD and TL models was 1.00 for the FADN population and 1.01 for the TFAS population. These scale elasticities reveal the presence of constant returns to scale. This suggests that, for the studied dairy farms, an increase in all inputs by a certain factor would result in an increase in output by the same factor. The variance parameter $\gamma$ was 0.99 in all 4 models and indicated that the vast majority (about 99\%) of the error variation in the production function was due to the inefficiency error $u_{i}$ and only $1 \%$ was due to the stochastic random error $\nu_{i}$. When the variance parameter is 0 , then no inefficiency is associated with the sampled dairy farm.

The likelihood ratio test for comparing the 2 functional forms rejected the null hypothesis of $\mathrm{CD}$ in favor of the TL model at the $5 \%$ significance level. Hence, the TL functional form was more appropriate than the CD functional form for both the FADN and TFAS samples.

\section{Impact of GI Nematode Exposure on Efficiency}

The null hypothesis, which assumes that inefficiencies are not related to GI nematode exposure (i.e., the parameter $\gamma$ and the inefficiency model parameters are jointly equal to zero), was rejected $(P<0.05)$ for all estimated models. The estimated coefficients of the inefficiency effect model showed a significant $(P<0.05)$ relationship between inefficiency and infection under the FADN and TFAS samples for both the CD and TL production functions. The coefficient indicated a positive effect of GI nematode exposure on the inefficiency levels. Plotting the average technical efficiency scores and ODR over time (Figure 2) clearly reveals that technical efficiency increases when the exposure to GI nematodes decreases and vice versa.

The likelihood ratio test favored the TL functional form. We, therefore, chose the TL model results to further explain the impact of GI nematode infections on the technical inefficiency. The calculated average marginal effect of exposure to GI nematodes indicated that an increase in exposure by 1 ODR was associated with a decrease of the technical efficiency by $0.01(1 \%)$ and $0.02(2 \%)$ for FADN and TFAS, respectively.

The estimates of the non-neutral inefficiency effect model (Table 3) illustrate how O. ostertagi infection was associated with the input variables. Although the likelihood ratio test is in favor of the neutral model, the estimates of the non-neutral model are also presented to complement the interpretation of the neutral model results. This provides a better understanding of how GI nematode infections are associated with the transformation of the input variables. The negative coefficients of the cross products in the TFAS sample (i.e., ODR $\times$ concentrate, $\mathrm{ODR} \times$ roughage, and ODR $\times$ dairy cows) indicated that exposure to GI nematodes did not induce inefficiency in the use of concentrates, roughage, and dairy cows. The positive coefficients of the cross products ODR $\times$ pasture, ODR $\times$ health, and ODR $\times$ labor indicated that the exposure to GI nematodes constrained the productivity of pasture, health costs, and labor. Although the FADN sample showed no significant effect of $O$. ostertagi on the technical inefficiency in the non-neutral model, the productivity of pasture and health were negatively affected by infection. 
Table 3. The maximum likelihood estimates for the parameters in the non-neutral stochastic frontier model in terms of the transcendental logarithmic (Translog) functional form for the Farm Accountancy Data Network (FADN, Brussels, Belgium) and Tiber Farm Accounting System (TFAS; Boerenbond, Leuven, Belgium) samples

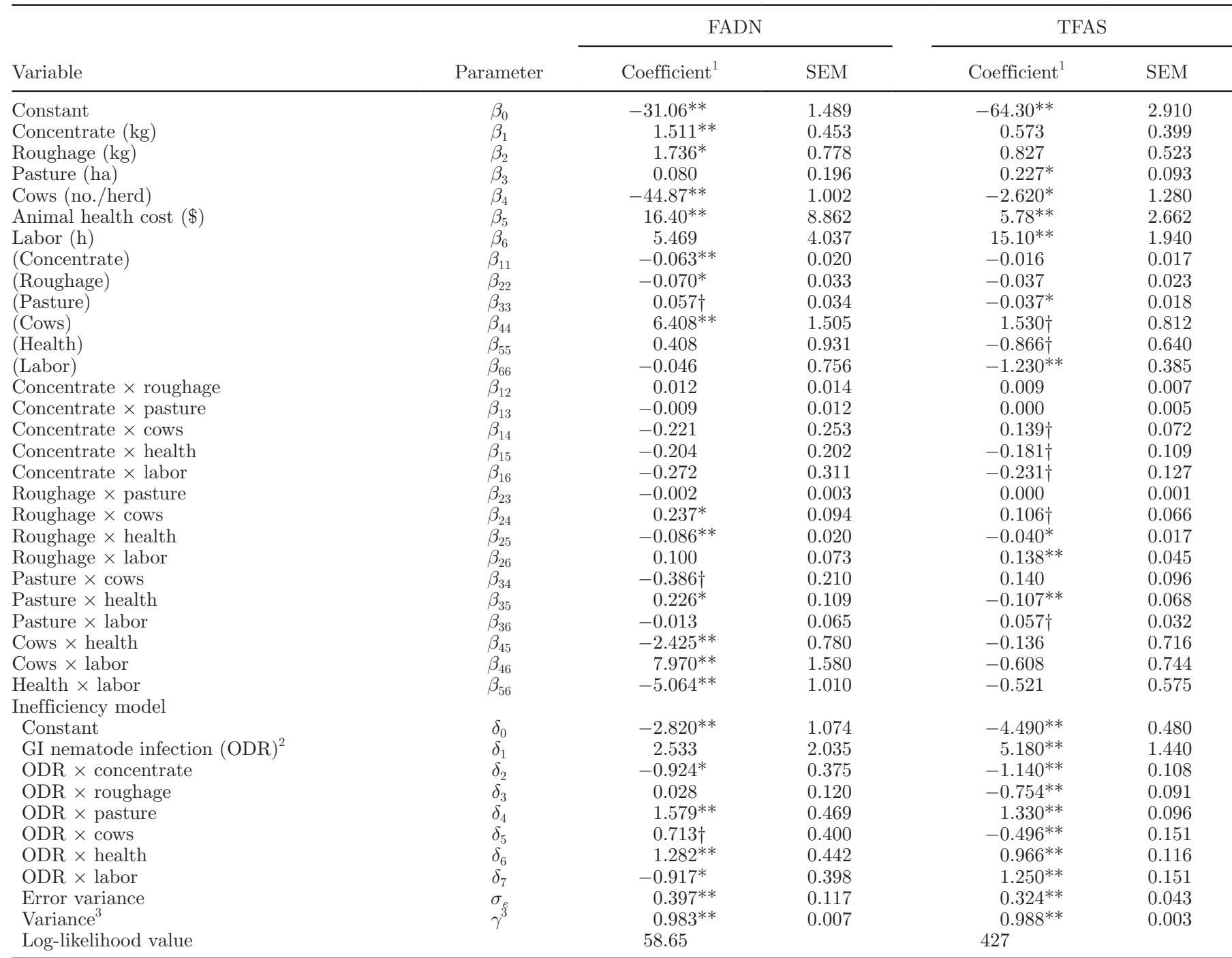

${ }^{1}$ Negative signs of coefficients represent reduction in inefficiency (or increase in efficiency).

${ }^{2} \mathrm{GI}=$ gastrointestinal; ODR $=$ optical density ratio.

${ }^{3}$ Gamma is the variance parameters associated with inefficiency. It is zero if no inefficiency exists in the traditional error term.

$\dagger P<0.10 ; * P<0.05 ; * * P<0.01$.

\section{DISCUSSION}

Although efficiency analysis has the potential to provide an overall image of productive efficiency, the results need to be interpreted with respect to methodological points of departure. The results may depend on the following: representativeness and accounting rules of the data set, number of inputs considered, functional forms of the frontier, and the specification of the inefficiency effect model.

First, our study has shown that a lower level of $O$. ostertagi infection is associated with the technical effi- ciency of dairy farms. The magnitude of the coefficients in the inefficiency effects model is relatively similar for both samples. In this study, we also compared the CD and TL production functions to investigate whether the functional form would affect the results. This did not appear to be the case, because the CD and TL functional form yielded similar coefficients in the production model. The TL functional form gives a better representation of the data according to the likelihood ratio test. However, our results indicate that the $\mathrm{CD}$ production function may also be an appropriate model for estimating the relationship between GI nematode 
infections and efficiency. This is interesting because the CD model is relatively easier to interpret and, in future research, it could be used to obtain the cost function from a production function. This allows the researcher to go back and forth between the cost frontier and the production frontier (Kumbhakar et al., 1991).

In our study, we used 1 output variable (milk production), the main output on specialized dairy farms. We incorporated 6 input variables, based on their effect on milk production, their relationship with GI nematode infections reported in the literature, and the farmer's ability to adapt these variables to control infections. One could argue that we do not fully describe the production model because certain variables may not be included. However, the excluded variables only affect the estimated coefficients of the production model if they are correlated with included variables. Furthermore, the more variables that are distinguished, the more data are required to obtain a statistically significant production model (Andor and Hesse, 2013). Finally, Fried et al. (1993) point out that if all inputs and outputs are included in the analysis, no matter or energy can be created or destroyed, resulting in unitary productivity scores for all units. Also, other studies (e.g., Coelli et al., 2007; Van Meensel et al., 2010b) selected variables to be included in the production model based on a preliminary econometric analysis.

In a previous study of Charlier et al. (2005), an increase in ODR from 25th to the 75th percentile (interquartile range $=0.271$ ) was associated with a reduction in milk production of $0.9 \mathrm{~kg} /$ cow per day. For FADN farms, a decrease of $O$. ostertagi by 0.271 ODR resulted in a technical efficiency increase of 0.003 and corresponded to an average milk production increase of $27(0.46 \%), 19(0.25 \%)$, and $9(0.10 \%) \mathrm{L} /$ cow per year in the low- (0-90), medium- (90-95), and high- (95-99) efficiency score groups, respectively. For TFAS farms, decreasing GI nematode exposure by 0.271 ODR resulted in a technical efficiency increase of 0.006 and corresponded to an increase in average milk production of $63(0.95 \%), 49(0.61 \%)$, and $23(0.26 \%)$ $\mathrm{L} /$ cow per year in the low- (0-90), medium- (90-95), and high- (95-99) efficiency score group, respectively. Our estimated relationship between GI nematode exposure and milk production differs from the results of previous studies (Sanchez and Dohoo, 2002; Charlier et al., 2005). Previous studies performed a linear regression between GI nematode exposure (ODR) and daily milk production, while controlling for several potential confounding variables. Also, in recent clinical trials, the average estimated effect of anthelmintic treatment against GI nematodes under European conditions was estimated at approximately $1 \mathrm{~kg} / \mathrm{cow}$ per day (Charlier et al., 2009a). The differences from our study may be explained by the inclusion of both direct and indirect effects of GI nematode infections on milk production in previous studies. The direct effect reflects the lower productivity of inputs, whereas the indirect effect accounts for reduced milk production caused by a lower input use, such as reduced feed intake. Reduced feed intake is considered to be an important mechanism of lowered performance in GI nematode-infected farms (Fox et al., 1989; Forbes et al., 2004). The advantage of using efficiency analysis is that direct and indirect effects can be distinguished. Our estimated direct effect is a milk loss of $0.13 \mathrm{~L} /$ cow per day. The remaining milk loss can then be attributed to reduced input use.

The results show that farms in the low-efficiency score group (technical efficiency score between 0 and 90) could increase their milk production by an average of $1,600 \mathrm{~L} / \mathrm{cow}$ per year if they would become fully efficient. For these inefficient farms, a decrease in infection over the interquartile range results in an average increase of milk production of $63 \mathrm{~L} /$ cow per year. This represents $3.8 \%$ of the potential increase in production through efficiency improvement. For farms in the highefficiency score group (technical efficiency between 95 and 99) the contribution to the total possible milk increase needed to become fully efficient (i.e., $338 \mathrm{~L} / \mathrm{cow}$ per year) was $6.7 \%$. The absolute direct effect of GI nematodes on milk production becomes smaller with increasing technical efficiency. But for the highly efficient farms that strive to increase their efficiency even more, GI nematode infection has a relatively greater effect than for inefficient farms.

This study assumes that infection affects the productivity of dairy farms. However, it should be noted that our analysis approach does not assess the direction of the causality. For goats, it has been reported that highly productive animals (potentially associated with higher efficiency) are more susceptible to infection (Chartier and Hoste, 1997). On the other hand, the non-neutral model in the current study indicated that the negative relationship between GI nematode infection and inefficiency was weakened when concentrate and roughage increased. It is generally accepted that improved nutrition results in lower susceptibility to GI nematode infection (Forbes et al., 2009; Hoste and Torres-Acosta, 2011; Houdijk et al., 2012).

This study opens several avenues for future research. The method used here to study the effect of GI nematode infections on the technical efficiency of dairy farms can also be used to study other infectious and production diseases. A few efficiency studies have focused on metabolic and reproductive disorders (Lawson et al., 2004a,b). Because the importance of several diseases cannot be compared between efficiency studies, it would be very useful to analyze multiple animal diseases in 
1 model (Lawson et al., 2004a). Further, the use of efficiency analysis yields efficiency scores that have limited information value for farmers and farm advisors. To yield more communicative results, budgeting techniques can be used in combination with efficiency analysis (Van Meensel et al., 2010b, 2012). At last, the role of management actions stayed unknown in the current study. Some studies have used efficiency analyses to study the effect of disease control strategies (Van Meensel et al., 2010a, Barnes et al., 2011; Hansson et al., 2011). Therefore, further research should explore the effect of management decisions on infection and efficiency for different types of farms to provide a more holistic decision support regarding GI nematode infections than current recommendations, which focus on reducing infection levels or increasing milk production alone.

\section{CONCLUSIONS}

This is the first study that shows the relationship between GI nematode infections and the technical efficiency of dairy farms. Efficiency analysis was used to associate the subclinical impact of GI nematode infections with the technical efficiency of dairy farms. The study showed that exposure to GI nematodes has a negative effect on the technical efficiency of dairy farms. Dairy farms with a high technical efficiency score had a relatively higher milk production benefit from lowering the level of GI nematode infection than their inefficient counterparts. The inefficiency caused by infection is rather small, but could be the last bit for highly efficient farms to become fully technically efficient. Our model supports that the incidence of GI nematode infections does not induce inefficiency in the use of concentrates, roughage, and dairy cows, but does have a negative effect on the transformation of pasture, health, and labor into milk production. Future research should explore the effect of management decisions on infection and efficiency and should study which management strategies best increase technical and economic efficiency on different types of farms.

\section{ACKNOWLEDGMENTS}

The work of Mariska van der Voort is supported by the Agency for Innovation by Science and Technology of Flanders (IWT Vlaanderen, 101357). The work of Johannes Charlier is supported by the EU FP7 GLOWORM project (grant agreement no. 288975CP-TPKBBE.2011.1.3-04).

\section{REFERENCES}

Andor, M., and F. Hesse. 2013. The StoNED age: The departure into a new era of efficiency analysis? A Monte Carlo comparison of
StoNED and the "oldies" (SFA and DEA). J. Prod. Anal. http:// dx.doi.org/10.1007/s11123-013-0354-y.

Bandyopadhyay, S., S. Mandal, K. K. Datta, P. Devi, S. De, A. K. Bera, and D. Bhattacharya. 2010. Economic analysis of risk of gastrointestinal parasitic infection in cattle in North Eastern States of India. Trop. Anim. Health Prod. 42:1481-1486.

Barnes, A. P., K. M. D. Rutherford, F. M. Langford, and M. J. Haskell. 2011. The effect of lameness prevalence on technical efficiency at the dairy farm level: An adjusted data envelopment analysis approach. J. Dairy Sci. 94:5449-5457.

Battese, G. E., and S. S. Broca. 1997. Functional forms of stochastic frontier production functions and models for technical inefficiency effects: A comparative study for wheat farmers in Pakistan. J. Prod. Anal. 8:395-414.

Battese, G. E., and T. J. Coelli. 1995. A model for technical inefficiency effects in a stochastic frontier production function for panel data. Empir. Econ. 20:325-332.

Bennema, S., J. Vercruysse, E. Claerebout, T. Schnieder, C. Strube, E. Ducheyne, G. Hendrickx, and J. Charlier. 2009. The use of bulktank milk ELISAs to assess the spatial distribution of Fasciola hepatica, Ostertagia ostertagi and Dictyocaulus viviparus in dairy cattle in Flanders (Belgium). Vet. Parasitol. 165:51-57.

Charlier, J., E. Claerebout, L. Duchateau, and J. Vercruysse. 2005. A survey to determine relationships between bulk tank milk antibodies against Ostertagia ostertagi and milk production parameters. Vet. Parasitol. 129:67-75.

Charlier, J., E. Claerebout, and J. Vercruysse. 2011. Parasites, internal: Gastrointestinal nematodes. Pages 258-263 in Encyclopedia of Dairy Sciences. Vol. 2. J. W. Fuquay, P. F. Fox, and P. L. H. McSweeney, ed. Academic Press, San Diego, CA.

Charlier, J., J. Höglund, G. von Samson-Himmelstjerna, P. Dorny, and J. Vercruysse. 2009a. Gastrointestinal nematode infections in adult dairy cattle: Impact on production, diagnosis and control. Vet. Parasitol. 164:70-79.

Charlier, J., B. Levecke, B. Devleesschauwer, J. Vercruysse, and H. Hogeveen. 2012a. The economic effects of whole-herd versus selective anthelmintic treatment strategies in dairy cows. J. Dairy Sci. 95:2977-2987.

Charlier, J., J. Troeng, J. Höglund, J. Demeler, K. Stafford, G. Coles, G. von Samson-Himmelstjerna, M. Merza, and J. Vercruysse. 2009b. Assessment of the within- and between-laboratory repeatability of a commercially available Ostertagia ostertagi milk ELISA. Vet. Parasitol. 164:66-69.

Charlier, J., M. van der Voort, H. Hogeveen, and J. Vercruysse. 2012b. ParaCalc ${ }^{\circledR}$ - A novel tool to evaluate the economic importance of worm infections on the dairy farm. Vet. Parasitol. 184:204-211.

Chartier, C., and H. Hoste. 1997. Response to challenge infection with Haemonchus contortus and Trichostrongylus colubriformis in dairy goats. Differences between high and low-producers. Vet. Parasitol. $73: 267-276$.

Coelli, T. J. 1996. A guide to FRONTIER Version 4.1: A computer program for frontier production and cost function estimation. CEPA working paper, No. 7/96. Dept. Econometrics, Univ. of New England, Armidale, Australia.

Coelli, T. J., L. Lauwers, and G. Van Huylenbroeck. 2007. Environmental efficiency measurement and the materials balance condition. J. Prod. Anal. 28:3-12.

Coelli, T. J., D. S. P. Rao, C. J. O'Donnell, and G. E. Battese. 2005. An Introduction to Efficiency and Productive Analysis. Springer, New York, NY.

Cook, W. D., and L. M. Seiford. 2009. Data envelopment analysis (DEA) - Thirty years on. Eur. J. Oper. Res. 192:1-17.

Darku, A. B., S. Malla, and K. C. Tran. 2013. Historical review of agricultural efficiency studies. Univ. of Lethbridge, Lethbridge, AB, Canada.

De Becker, R. 2007. Het Vlaamse LandbouwMonitoringsNetwerk: Wat en Hoe? Afdeling Monitoring en Studie, Brussels, Belgium.

Delafosse, A. 2013. The association between Ostertagia ostertagi antibodies in bulk tank milk samples and parameters linked to cattle reproduction and mortality. Vet. Parasitol. 197:212-220. 
Farrell, M. J. 1957. The measurement of productive efficiency. J. Royal Stat. Soc. A 120:253-290.

Forbes, A. B., C. A. Huckle, and M. J. Gibb. 2004. Impact of eprinomectin on grazing behaviour and performance of dairy cattle with sub-clinical gastrointestinal nematode infections under continuous stocking management. Vet. Parasitol. 125:353-364.

Forbes, A. B., M. Warren, M. Upjohn, B. Jackson, J. Jones, J. Charlier, and M. T. Fox. 2009. Associations between blood gastrin, ghrelin, leptin, pepsinogen and Ostertagia ostertagi antibody concentrations and voluntary feed intake in calves exposed to a trickle infections with $O$. ostertagi. Vet. Parasitol. 162:295-305.

Fox, M. T., D. Gerrelli, S. R. Pitt, D. E. Jacobs, M. Gill, and D. L. Gale. 1989. Ostertagia ostertagi infection in the calf: Effects of a trickle challenge on appetite, digestibility, rate of passage of digesta and liveweight gain. Res. Vet. Sci. 47:294-298.

Fried, H. O., C. A. K. Lovell, and S. S. Schmidt. 1993. The Measurement of Productive Efficiency: Techniques and Applications. Oxford University Press, New York, NY.

Hansson, H., M. Szczensa-Rundberg, and C. Nielsen. 2011. Which preventive measures against mastitis can increase the technical efficiency of dairy farms? Animal 5:632-640.

Hoang, V.-N., and T. T. Nguyen. 2013. Analysis of environmental efficiency variation: A nutrient balance approach. Ecol. Econ. $86: 37-46$.

Hoste, H., and J. F. J. Torres-Acosta. 2011. Non chemical control of helminths in ruminants: Adapting solutions for changing worms in a changing world. Vet. Parasitol. 180:144-154.

Houdijk, J. G. M., I. Kyriazakis, A. Kidane, and S. Athanasiadou. 2012. Manipulating small ruminant parasite epidemiology through the combinations of nutritional strategies. Vet. Parasitol. 186:3850.

Kelly, E., L. Shalloo, U. Geary, A. Kinsella, F. Thorne, and M. Wallace. 2012. The associations of management and demographic factors with technical, allocative and economic efficiency of Irish dairy farms. J. Agric. Sci. 150:738-754.

Kelly, E., L. Shalloo, U. Geary, A. Kinsella, F. Thorne, and M. Wallace. 2013. An analysis of the factors associated with technical and scale efficiency of Irish dairy farms. Int. J. Agric. Manag. 2:149-159. http://dx.doi.org/10.5836/ijam/2013-03-04.

Kumbhakar, S. C., S. Ghosh, and J. T. McGuckin. 1991. A generalized production frontier approach for estimating determinants of inefficiency in U.S. dairy farms. J. Bus. Econ. Stat. 9:279-286.

Kumbhakar, S. C., and C. A. K. Lovell. 2000. Stochastic Frontier Analysis. Cambridge University Press, Cambridge, UK.

Lawson, L. G., J. F. Agger, M. Lund, and T. Coelli. 2004a. Lameness, metabolic and digestive disorders, and technical efficiency in Danish dairy herds: A stochastic frontier production function approach. Livest. Prod. Sci. 91:157-172.

Lawson, L. G., J. Bruun, T. Coelli, J. F. Agger, and M. Lund. 2004b. Relationship of efficiency to reproductive disorders in Danish milk production: A stochastic frontier analysis. J. Dairy Sci. 87:212224.

Liu, J. S., L. Y. Y. Lu, W.-M. Lu, and B. J. Y. Lin. 2013. Data envelopment analysis 1978-2010: A citation-based literature survey. Omega 41:3-15.

Moreira López, V. H., and B. E. Bravo-Ureta. 2009. A study of dairy farm technical efficiency using meta-regression: An international perspective. Chilean J. Agric. Res. 69:214-223.

Sanchez, J., and I. Dohoo. 2002. A bulk tank milk survey of Ostertagia ostertagi antibodies in dairy herds in Prince Edward Island and their relationship with herd management factors and milk yield. Can. Vet. J. 43:454-459.

Sargison, N. 2011. Responsible use of anthelmintics for nematode control in sheep and cattle. In Pract. 33:318-327.

Schmidt, P. 2011. One-step and two-step estimation in SFA models. J. Prod. Anal. 36:201-203.

Simar, L., and P. W. Wilson. 2007. Estimation of inference in twostage semi-parametric models of production processes. J. Econ. 136:31-64.

Thornton, P. K. 2010. Livestock production: Recent trends, future prospects. Phil. Trans. R. Soc. Lond. B Biol. Sci. 365:2853-2867.

van der Voort, M., J. Charlier, L. Lauwers, J. Vercruysse, G. Van Huylenbroeck, and J. Van Meensel. 2013. Conceptual framework for analysing farm-specific economic effects of helminth infections in ruminants and control strategies. Prev. Vet. Med. 109:228-235.

Van Meensel, J., A. Kanora, L. Lauwers, J. Jourquin, L. Goossens, and G. Van Huylenbroeck. 2010a. From research to farm: Ex ante evaluation of strategic deworming in pig finishing. Veterinární Medicína 55:483-493.

Van Meensel, J., L. Lauwers, I. Kempen, J. Dessein, and G. Van Huylenbroeck. 2012. Effect of a participatory approach on the successful development of agricultural decision support systems: The case of Pigs2win. Decis. Support Syst. 54:164-172.

Van Meensel, J., L. Lauwers, and G. Van Huylenbroeck. 2010b. Communicative diagnosis of cost-saving options for reducing nitrogen emission from pig finishing. J. Environ. Manage. 91:2370-2377.

Wang, H. J., and P. Schmidt. 2002. One-step and two-step estimation of the effects of exogenous variables on technical efficiency levels J. Prod. Anal. 18:129-144.

Wilson, P., D. Hadley, and C. Asby. 2001. The influence of management characteristics on technical efficiency of wheat farmers in eastern England. Agric. Econ. 24:329-338. 